\title{
Leadership power discrepancies and worker morale: A test of ecological dissonance theory
}

\author{
DUANE I. MILLER, SHANG LIN, J. MARTIN GIESEN, DAVID L. MCMILLEN, \\ ELISABETH WELLS-PARKER, and PAT SANDERSON \\ Mississippi State University, Mississippi State, Mississippi \\ and \\ JEFF S. TOPPING \\ San Joaquin Delta College, Stockton, California
}

\begin{abstract}
The present study attempted to develop a new measure of ecological dissonance (Miller, Topping, \& Wells-Parker, 1989) for an organization and to assess its relationship with measures of alienation, involvement, and satisfaction. Questionnaires were administered to 94 faculty members at Mississippi State University. It was hypothesized that respondents experiencing greater ecological dissonance would also show higher alienation scores, lower involvement scores, and lower satisfaction scores with regard to their jobs; it was also hypothesized that the ecological dissonance levels would vary among the four influence systems (department head, dean, provost, and president of university) and would affect morale to different degrees. Correlational analyses indicated significant correlations between the measures of ecological dissonance, alienation, involvement, and satisfaction. A regression analysis revealed that the ecological dissonance generated within the department head's influence system was the best predictor of morale. Additionally, a repeated measures analysis of variance revealed that the four influence systems differed significantly in ecological dissonance. The results supported the hypotheses and ecological dissonance theory.
\end{abstract}

Ecological dissonance theory (see Miller, Topping, \& Wells-Parker, 1989) was developed to provide an explanation for the motivational consequences that occur when environmental systems or environmental and cognitive systems are in conflict. An example of the type of conflict of concern is that which occurs when laws, such as the mandatory seat belt law, are at variance with the behavioral systems of many of the individuals covered by the law. It was proposed that this conflict energizes forces directed at the reduction of the ecological tension being generated by the conflict; energy expended in dealing with the conflict is a function of the amount of dissonance in the ecological systems, which in turn is a function of the proximity and power of the systems in conflict. Ecological dissonance can be reduced by mechanisms such as bargaining, mediation, legal adjudication, and increased formalization; until removal of the tension is accomplished, there will be pressure on the individuals of the ecologically imbalanced system. Finally, this pressure will be manifested in several ways, including low worker morale.

Recently, several studies have examined ecological dissonance theory (Miller, Burton, Giesen, \& Topping, 1990; Miller, Majors, Giesen, \& Topping, 1990; Miller $\&$ Topping, 1991), and the research has provided weak but statistically significant support for the theory.

Requests for reprints should be addressed to D. I. Miller, P.O. Box 6161, Mississippi State, MS 39762-6161.
The purpose of the present study was to examine the relationship between another measure of ecological dissonance and worker morale. The ecological dissonance measure was generated by an application of "bases of power measure" developed by Bachman (Price, 1972). Specifically, subjects were asked to give their opinions about the sources of power used by their superiors and the sources of power they felt their superiors should be using. The difference between the perceived control system and the desired control system was the measure of ecological dissonance.

It was hypothesized that larger ecological dissonance scores would be associated with more alienation from work, lower job satisfaction, and lower job involvement (i.e., lower morale scores).

\section{METHOD}

\section{Subjects}

Subjects consisted of 94 faculty members in various departments at Mississippi State University. The names of the subjects were selected systematically through the 1991 Mississippi State University Faculty, Staff, and Student Telephone Directory. No incentive was offered to the subjects.

\section{Procedure and Materials}

The survey, which was mailed to the subjects, consisted of the Index of Power Discrepancy and the Index of Worker Morale (including the Job Satisfaction Index, the Work Alienation Scale, and the Index of Job Involvement). 
The Index of Power Discrepancy was developed in an attempt to obtain a measure of ecological dissonance for an organization. Questions were taken from French and Raven's (1959) theory of bases of power found in the Bachman (1968) study. The instructions for the questionnaires were modified so that an Index of Power Discrepancy could be created. The subjects were instructed to rank the five bases of power (reward, coercive, referent, legitimate, and expert) in terms of the power they would prefer their supervisors to use in leading their work group. They were also instructed to rate these five bases of power as reasons they do things as requested by their department head, dean, provost, and president of the university. To create an ecological dissonance score, the quantitative difference between the desired and perceived control systems was determined. By taking the absolute value of every difference number and then adding the five difference numbers together, an ecological dissonance number for each respondent was generated.

The Index of Worker Morale contained 18 items from Brayfield and Rothe's (1951) Job Satisfaction Index, 5 items from Miller's (1967) Work Alienation Scale, and 6 items from Lodahl and Kesner's (1965) Index of Job Involvement. A scale ranging from 1 (strongly disagree) to 4 (strongly agree) was used to assess the responses given by the subjects to those items, which are available from the senior author.

\section{RESULTS}

Pearson product-moment correlation coefficients were calculated between each of the measures of ecological dissonance (generated from the four influence systems of the department head, the dean, the provost, and the president of the university), the Work Alienation Scale, the Index of Job Involvement, and the Job Satisfaction Index. A regression analysis demonstrated that the ecological dissonance in the department head's position was the best predictor of each of the three measures of worker morale.

Correlation analyses of the department head's position revealed a significant correlation between ecological dissonance and job satisfaction $[r(92)=.43, p<.01]$. In the dean's position, there was a significant correlation between ecological dissonance and work alienation $[r(92)=.30$, $p<.01]$. Examination of the provost's position revealed a significant correlation between ecological dissonance and work alienation $[r(92)=.26, p<.01]$ and a significant correlation between ecological dissonance and job satisfaction $[r(92)=-.20, p<.05]$. The analysis of the president's position revealed no significant correlations.

The ecological dissonance means for the positions of department head, dean, provost, and president were 2.60 , $3.00,3.67$, and 3.22 , respectively. A repeated measures analysis of variance indicated that the means were significantly different $[F(3,279)=6.77, p<.01]$.

\section{DISCUSSION}

The results of the present study supported the hypothesis that respondents who had experienced ecological dissonance, as measured by the
Index of Power Discrepancy, would also experience alienation, lack of involvement, and dissatisfaction with their jobs. The ecological dissonance in the department head's, dean's, and provost's influence systems was significantly related to at least one of the three measures of faculty members' morale. This relationship did not hold for the president's position, however, even though ecological dissonance levels for that position were second only to the provost's position in intensity. In contrast, the ecological dissonance levels for the department head's position were the lowest while yielding the highest correlations with the measures of morale.

A possible explanation for these results might be found in the proposition of ecological dissonance theory (Miller et al., 1989), which states, "The amount of ecological dissonance is a function of the proximity and power of the systems in conflict, with the greatest dissonance occurring between systems of equal power which are functionally close to each other" (p. 164). If one assumes that the Index of Power Discrepancy measured only part of the ecological dissonance that existed in the situation, one could argue that the department head's position actually contained the highest ecological dissonance potential because this position is functionally the closest to the human system in question. That is, because the department head has the most immediate power over the faculty member, any dissonance generated by conflict between the systems involving the department head would be intensified. If this is correct, the development of measures of functional distance for use in future studies would enable researchers to partial out the effects of functional distance from the relationship between the Index of Power Discrepancy and measures of morale.

\section{REFERENCES}

BaChman, J. G. (1968). Faculty satisfaction and the dean's influence: An organization study of twelve liberal arts colleges. Journal of Applied Psychology, 52, 55-61.

Brayfield, A. H., \& Rothe, H. E. (1951). An index of job satisfaction. Journal of Applied Psychology, 35, 307-311.

French, P., \& RAVEN, B. (1959). The bases of social power. In D. Cartwright (Ed.), Studies in social power (pp. 150-167). Ann Arbor, MI: Institute for Social Research.

LODAHL, T. M., \& KeSNER, M. (1965). The definition and measurement of his job involvement. Journal of Applied Psychology, 49, 24-33.

Miller, D. I., Burton, B., Giesen, M., \& Topping, J. S. (1990). Ecological dissonance theory and criterion validity of the Hooper equal opportunity measure. Psychological Reports, 66, 1155-1158.

Miller, D. I., Majors, M., Giesen, M., \& TopPing, J. S. (1990). The Hooper equal opportunity measure: An operational definition of ecological dissonance theory. Bulletin of the Psychonomic Society, 28, 164-166.

Miller, D. I., \& ToPPING, J. S. (1991). Factors of ability, communication, grievances, and personal optimism as predictors of student satisfaction, involvement, and alienation: An ecological dissonance interpretation. Bulletin of the Psychonomic Society, 29, 19-20.

Miller, D. I., Topping, J. S., \& Wells-Parker, E. N. (1989). Ecological dissonance and organizational climate. Psychological Reports, 64, 163-166.

Miller, G. A. (1967). Professions in bureaucracy: Alienation among industrial scientists and engineers. American Sociological Review, 64, 755-768.

PRICE, J. L. (1972). Handbook of organizational measurement. Lexington, MA: Heath.

(Manuscript received December 5, 1991.) 